Instructions for authors, subscriptions and further details:

\title{
http://mcs.hipatiapress.com
}

\section{Impersonations. The Artifice of Brahmin Masculinity in South Indian Dance}

Elena Duque ${ }^{1}$

1) Universitat de Barcelona, Spain

Date of publication: February $21^{\text {th }}, 2020$

Edition period: February 2020- June 2020

To cite this article: Duque, E. (2020). Impersonations. The Artifice of Brahmin Masculinity in South Indian Dance. [Review of the book]. Masculinities and Social Change 9(1), 109-110. doi:

10.17583/MCS.2020.5175

To link this article: http://dx.doi.org/10.4471/MCS.2020.5175

PLEASE SCROLL DOWN FOR ARTICLE

The terms and conditions of use are related to the Open Journal System and to Creative Commons Attribution License (CC-BY). 

MCS - Masculinities and Social Change Vol. 9 No. 1 February 2020 pp. $109-110$

\section{Reviews (II)}

Mruthinti Kamath, H. (2019). Impersonations. The Artifice of Brahmin Masculinity in South Indian Dance. Berkeley, CA: University of California Press.

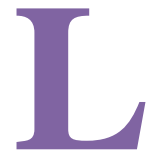

a masculinidad se ha analizado de forma amplia desde un prisma sobretodo occidental, básicamente centrándose en la hegemonía del hombre heterosexual de raza blanca. A eso hace referencia la autora del libro cuando empieza a analizar la construcción de la masculinidad en la cultura Brahmin. Refieréndose a Connell (1995), argumenta que existen diferentes formas de entender la masculinidad más allá de este esquema occidental predominante.

De esta manera a lo largo del libro profundiza en la ruptura que suponen los hombres que practican una determinada danza en la Índia a la masculinidad dominante. El análisis realizado, desde una perspectiva metodológica etnográfica, recoge las particularidades de esta danza y su impacto en la definición de las identidades de género masculinas en la India.

Por un lado, se pone de manifiesto el poder y la presencia que tiene la figura masculinidad hegemónica brahman en la India ya que posee una fuerza simbólica y económica muy importante. A pesar de esta presencia, la autora del libro argumenta que esta situación está cambiando debido a procesos como la globalización y la transnacionalidad. Gracias a estos procesos están surgiendo modelos de masculinidad no normativos que están desafiando los esquemos tradicionales más presentes en la India. Para explicar con detenimiento este cambio utiliza el concepto de impersonation, que hace referencia a la "suplantación" del modelo de masculinidad hegemónica tradicional.

Para los men's studies la contribución que se expone en este libro supone ofrecer conocimiento innovador poco abordado anteriormente. La 
110 Duque-Sánchez - Impersonations [Book Review]

combinación de perspectivas diversas como los estudios culturales, la metodología cualitativa y los estudios de género aporta elementos que ilustran realidades escasamente abordadas que ofrecen nuevas posibilidades para romper con mitos de género equivocados.

Elena Duque Sánchez

elenaduquesa@ub.edu 